\title{
The Magnificent AI \& AR Combinations: Limits? Gorgeous Imperfections!
}

Claudio Marchese

Antonino Nastasi

\section{Abstract}

Time and Space persist, in the digital age, as coordinates in which human presence is located. We will analyze some forms in which it is demonstrated "scenarios" concerning: a) spatial prefigurations of human 'refuges'; a transition place between external and internal. Phenomenology experienced, in moving through the atrium of Alberto Campo Baeza's school in Loeches, crossed by the pupils. Movements punctuated, in opposite directions, by natural light variations and related shadows that continuously reconfigure it. AR b) measurements, regarding the astral motion of a satellite and shadow creations, revealed through light features. Variations defining the possibility in measuring time, due to three "bodies", one that illuminates, another that is illuminated, and an intermediate one, receiving the shadow. c) relationships, where Exalt and Hologram, evoke in AR sequences the preservation of species, in which we are already protagonist, and in '2001: A Space Odyssey', struggling with Al.

Keywords

prefigurations, measurements, relationships, space, time.

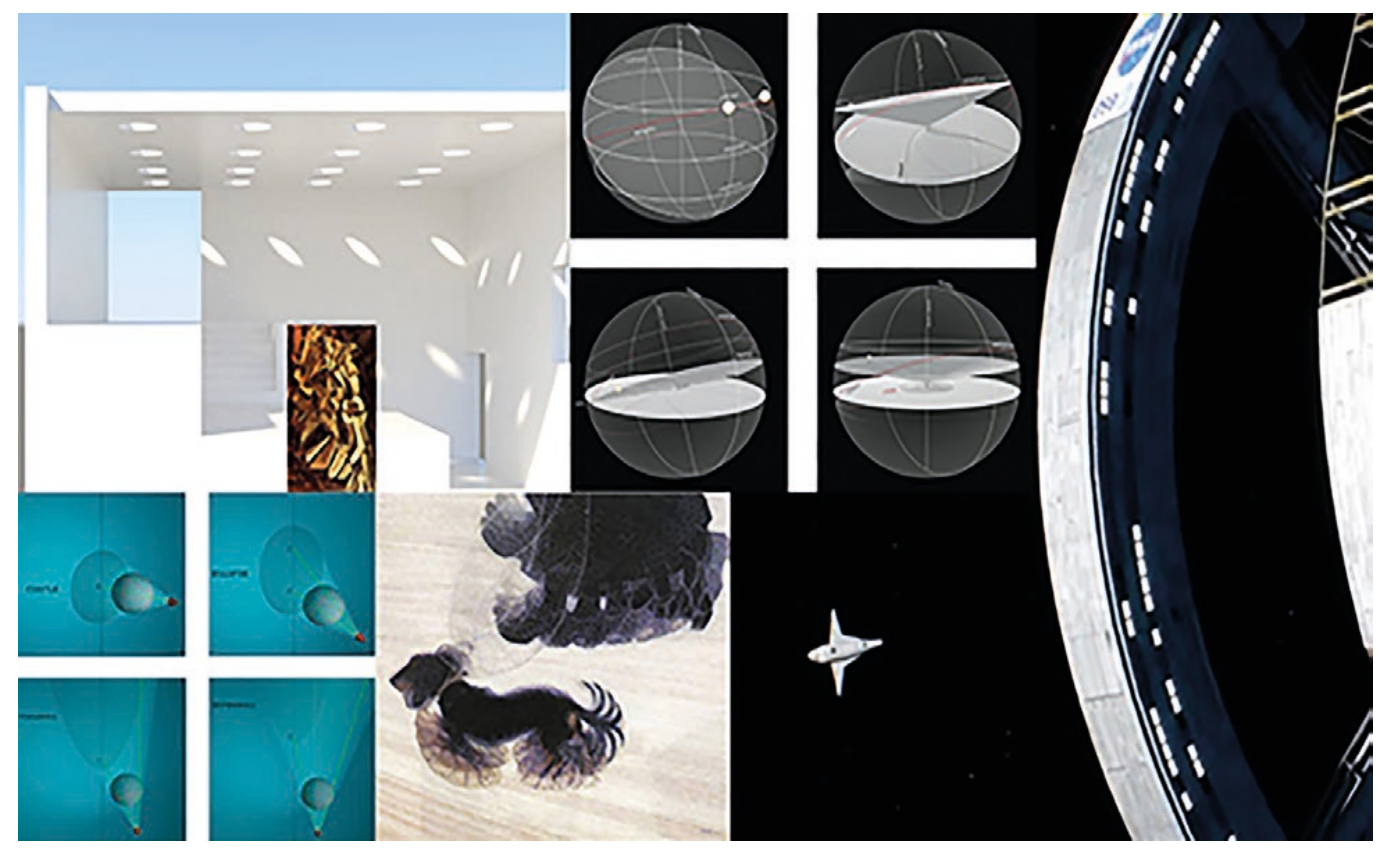




\section{Prefigurations}

When Giedion published his 'Space, Time and Architecture', it was sanctioned the intrinsic Architectural relationship with the two vital components, space and time, in which the human presence is sited in the world. Humanity becomes aware of itself, as well as in the form of relationships between individuals of the same species and as well with other subjects, animate and inanimate that constitute the living environment in which one moves, measured through his proportions: this we call Space.

Space, a stable entity, yet varying within the time ordinate, was somewhat immediately revealed to man through its cyclical manifestations. Day and night sequences taught man the art of prefiguration, making him feel set in and even cable in forecasting. Prefiguring desired events, essential for man's existence, brought him to draw on the walls of his first abode caves, essential sketches representing the phase sequences of hunting and gathering food. With this, man is affirmed as a species capable in elaborating paths going from aspiration to the realization of the event. Didactics, initiation rite, affirmation of superiority over other species, are all in the graffiti of the Altamira caves! The thirst for knowledge induced man to move away from his cavern refuge, becoming an explorer of the world. He searches for other shelters for the night and bad weather, rather than a possible return to his cave. The trees house him. First above and then even under, becoming more brave, strengthened by the security of the power of fire. Here were invented the first forms of huts, originated by bending the branches to the ground, illustrated by Abbot Lougier and treatise writers. In the Renaissance, the symbolic hemispherical shape, which previously was raised for some time in the form of a dome, was already mature to find an even more daring and symbolic constructive form, as advocated in the phrase of Filippo Brunelleschi that, regard to the dome of Santa Maria del Fiore in Firenze, states: "[...] la fece si ampia e gonfia da coprir tutti li popoli toscani' (Manetti, 'Le vite'). The emblematic value assumed by this dome is therefore recognized, which Brunelleschi explained it to his workers with the model of the chalices. The model was intuited by the structure of a vegetable, demonstrating thus the ability to transfer experiences from one world to another. The transitivity of such fantastic inventions was also undertaken generously by the contemporary genius Leonardo. Due to our reasoning, however, what interests us most is basically the prefigurative capacity of the model that holds within itself the principle of doubling, pretending lightness, and hides the grandeur of the structures from the view. As we know, thanks to the invention of the herringbone brick apparatus, with the mutual contrast immediately stabilizing, the dome can be built and so high, without temporary support ribs. In the same period the art of prefiguration recognizes in Leon Battista Alberti the most convinced supporter. Which, practicing the exact form with the field construction drawings, frees the designer from following the construction site. What point have we reached today in prefigurative art?

The control of architecture spatial outcomes, in prefiguration, have reach such sophistications as to bring the user into the most complete simulation of real space and in the condition of being able to act in it; therefore, in space, time and modifying it through the virtualization, which we call Augmented Reality. This, however, highlights that even in moving in real spaces within a distractive way could hardly be perceived as the simulated one, leading us perhaps even beyond our own wishes. A tool that has been tested for decades within programs and technologies available to everyone, is what in some programs is called 'Fly through'. It's true that it does not allow us to feel the warmth of sunlight and similar complexities. Enrolls itself as a perfect duplicate of the buildable but, actually, diminishes it. However, this modest and parsimonious technology feature describes even greater poetry. The 'Fly through', a devise in the field of design aids, allows to configure and display what is the revealer of architectural space: which is light with its variations, a fundamental material, and the gradation of shadows on surfaces. A choice in Architecture for the color of white, which elates, in its monochromatic, life that flows within and aside us, has been defined in that role wisely by Aldo Rossi assigning thus the expression " to be the fixed scene of life", used for the first time in the school of Broni and characterizing his public architecture. The school foyer in Loeches of Alberto Campo Baeza presented in the video, a linear and monochro- 


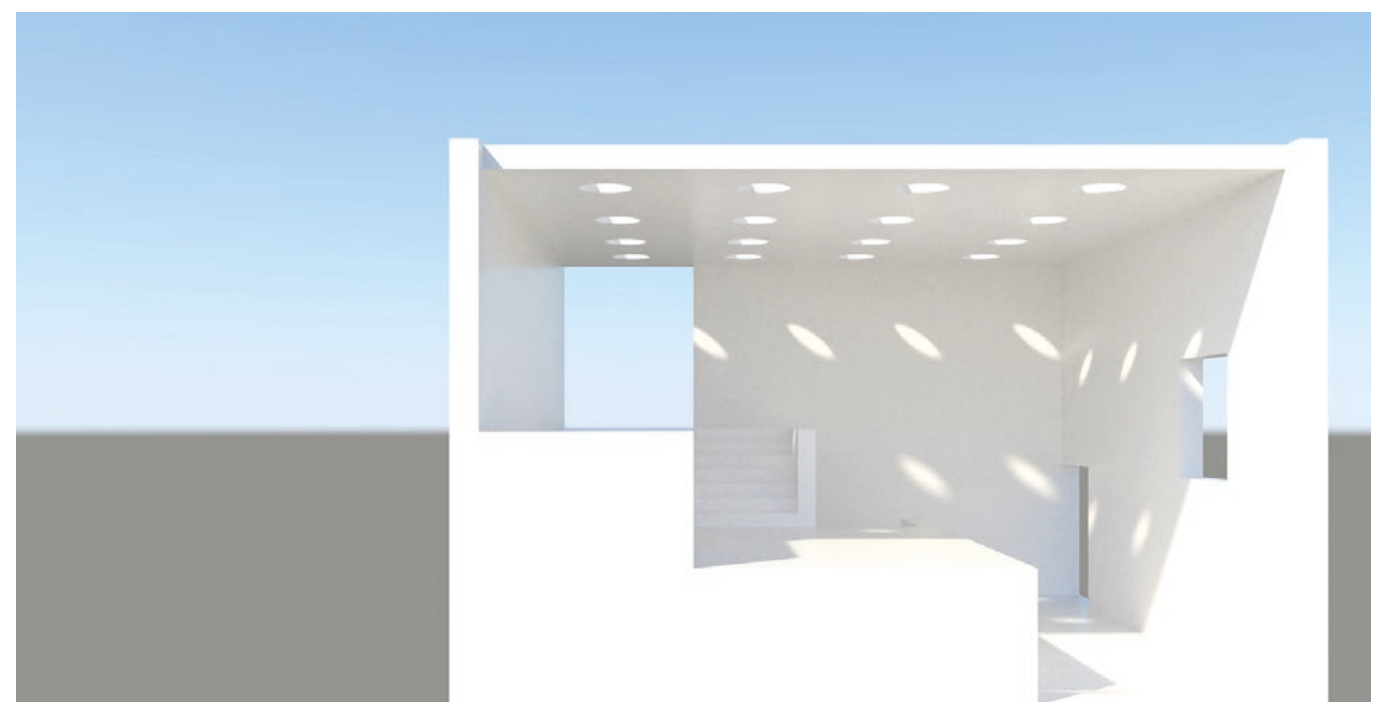

matic film sequence, is an emblematic case which recognizes the values mentioned above and testifies the designer's work experience who wisely displaces the light sources, capturing it within the architectural space continually reconfigured. The cyclical daylight passage will restore to the students, who occupy the space of the school hall, two significant moments of their day: entering and leaving the school. The rain of light coming from the large circles piercing the foyer ceiling, as the sunlight intensity varies, accompanies two moments of the student movements in the atrium space. In going in at school, the light captured at dawn, not very intense, escorts the students towards the interior, creating a mandatory condition for concentrating on study activities. In coming out the luminous intensity of the midday sun announces the outside both with the disappearance of the ceiling due to the sun at the zenith conveying a great intensity of light and with the dislocation of the windows that focus the external ground, horizon and sky, respectively from the upper, intermediate and lower exit floor of the atrium. This declares the resumption of the relations with the materiality of the world, due to cognitive essence elaboration mediated by collective activity and promoted learning.

\section{Measurements}

An apparent star orbits the sphere, Earth. Moving along the trajectory of its orbit, relating the planet to the system that both belong to and from which receives light. A dynamics obtained by imposing laws of movement in an adequate program reproducing, in simulation, a portion of the Apparent Solar System complexity.

This allows us to view from the outside and in a faster way, the effects induced by the established relationalities, in the subsequences of the reciprocal recurrence displacements. It is thus possible to 'observe' from a privileged point of view, putting our eye outside the system in which we are immersed, the dynamics of the apparent reality produced on our planet by the mutual dislocations of the spherical bodies mentioned above. It emerges, from the study, how the same exact configuration repetition of the two bodies, in relation to each other, occurs within cyclical cadences, determining variations that affect the temporal illumination quantities of the planet portions. The Earth, receives on its portions the shadow cast, illuminated by the very distant Sun, from which the light emanates. The 'imperfection' of the orbits, not circular, but elliptical, determined by the gravitational forces, generating the perpetuation of the movement, with the functioning of the gravitational forces, as a sort of springs that cyclically load and unload, allows, in a system equipped of substantial energy permanence, to cyclically replicate the reciprocal configurations passing through the 'infinite' others, following one after another. Spheres, representing stars and planets, moving away and getting closer, reveal the formation of particular conditions, in relation to another 'non-regularity', 

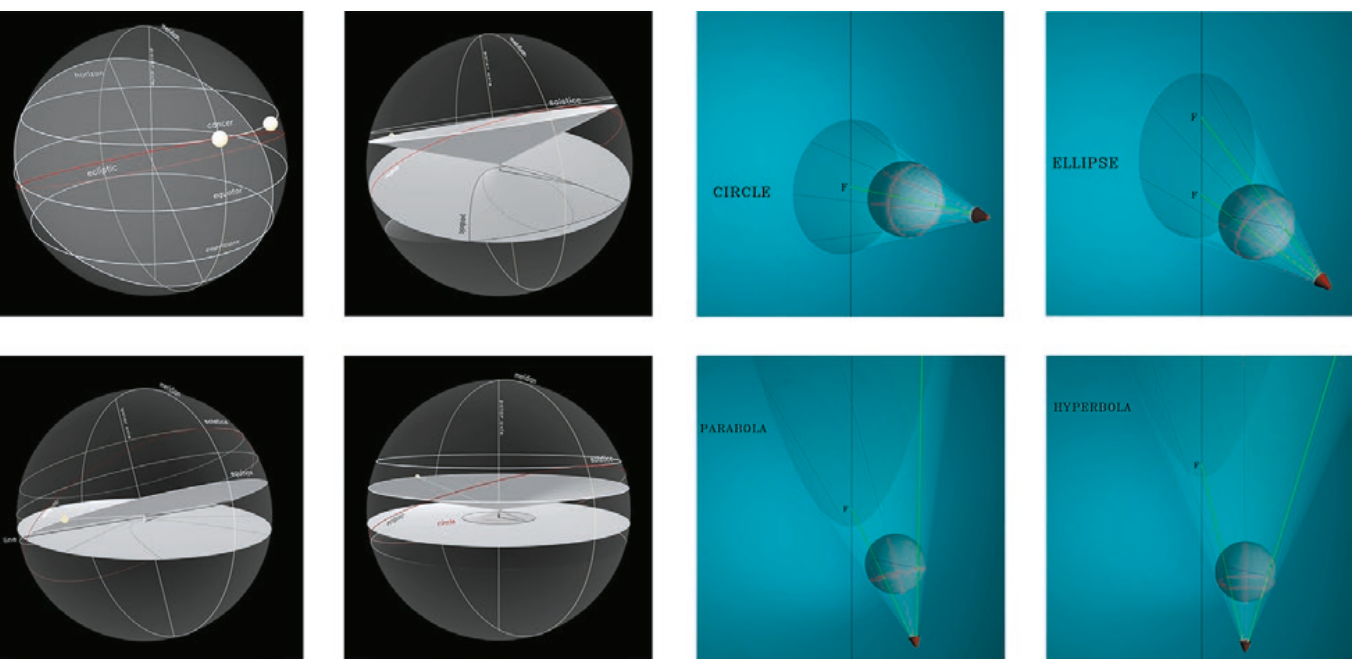

due to the different inclination of the rotation axes of the planets. This demonstrates, in our virtual model of the apparent celestial motions, an unequal distribution of light as well as shadows cast on the various portions of the Earth's surface. Something that we have been aware of for thousands of years and of which, thanks to computer science, we can now simulate with adequate authenticity. This allows to represent the apparent celestial sphere in which we are immersed, through the perceptual measurements of it. Unique measurements identify days in which the amount of light and darkness are equal (equinoxes) and two other days, in which respectively, lightness lasts longer and conversely less (solstices). The empirical model displays how these phenomena are the manifestations of the apparent world, as a result of the 'rotations' of the planets around their axis and of the 'revolutions', consisting in the elliptical orbit path movements. The Earth respect to the Sun and the Moon respect to the Earth. The video animation facilitates the understanding of shadow projections within the theory of conic sections. On one hand an imaginary shadow cone is cut by the plate of a sundial, while on the other the shadow of a sphere is projected on a plane demonstrating the Theorem of Dandelin-Quetelet. An aid of great importance, the scientific knowledge combined with empiricism, determined for example many actions carried out in agriculture, classifying the most propitious periods for sowing, other practices inherent to cultivating, as well as the most appropriate time for harvesting.

\section{Relationships}

A big wheel, the orbiting space station and the explorer spacecraft 'dance' in Stanley Kubrick's '200I A Space Odyssey', to the notes of the Straussian 'Blue Danube'. Choosing this captivating sequence, fragment of the narrated story, it is undertaken a reflection on the relationship between man and artificial intelligence.

The success of the mission is entrusted to the artificial intelligence of HAL 9000, the supercomputer supporting the human crew of the Discovery, as well as the management with the scientist's hibernation on board, during the journey in approaching Jupiter.The exploration was decided after the discovery in a Moon crater of a monolith, clearly extraterrestrial. Enigmatic, the monolith, which sends and receives signals from Jupiter. The true mission essence, started only for exploration by the crew members, is acknowledged by the computer on-board that has ears and eyes throughout the ship, interrelating with humans. Such was implemented in order to make the on-board computer, among other things, also the human guarantor, a sort of their wet nurse. But, every time you rely on something, you also lose a little bit of your individual freedom, ending up at the mercy of it. Now, in coincidence with a damage repaired with an external human intervention, another malfunction relegated the astronaut outside, with his small hull, whose destiny ended up in getting lost in space, once the oxygen had finished for him, losing the commands. Only one astronaut remains in 
Fig. 3. The frame is taken from the site: fantascienzaitalia.com. Page dedicated to the film 2001: A Space Odyssey by S. Kubrick in occasion of the 50 th anniversary re-release in theaters.

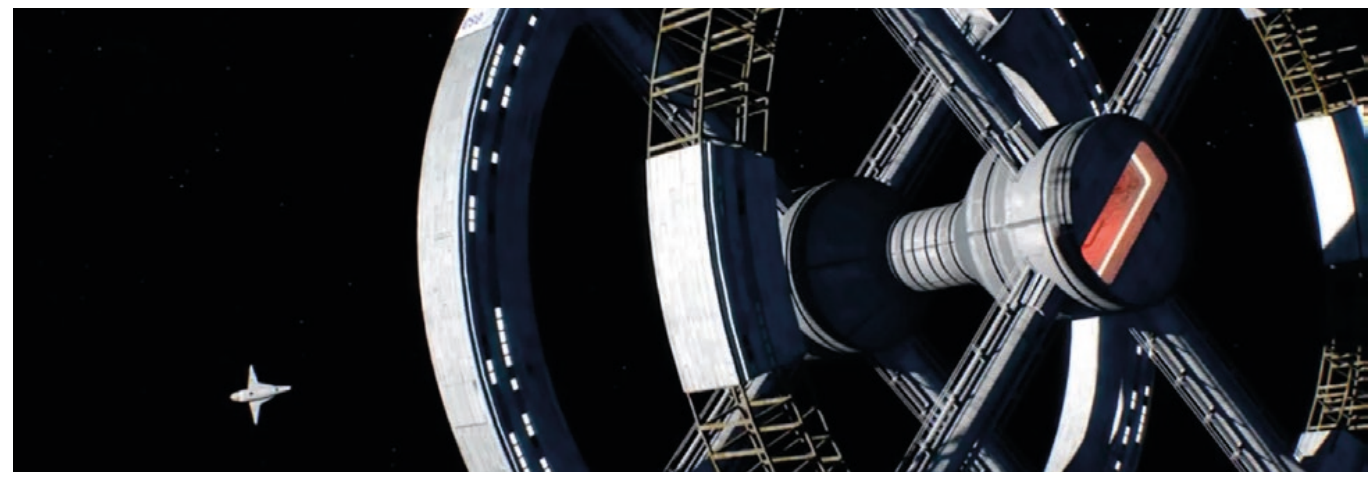

the spaceship with active vital functions, who must program HAL 9000's rejection in order to revitalize the scientists, and reach the site where the exploration should be undertaken by the entire crew. The human man, drawn by this refusal, understands the danger constituted by the 'protective' protocol used by the computer and decides to deactivate it. Therefore, engages a fight of unequal cunning with HAL 9000. If it wasn't for the human factor of the non-linear intelligence endowment, this allows him to have the upper hand in disabling the memory cards. Thus significantly regresses HAL 9000, verified by humming a childish song. The first information was taught to him by his inventor. It was exactly the contradiction between the task of collaborating with humans and the incongruous prohibition, that provided the true crew mission ending in disrupting HAL 9000, and with what could have ensued, if not disabled by man.

\section{Conclusions}

(Prefigurations) It is clear, now, how the authors feel that the poetry of architecture can be unacknowledged, consequential of the augmented reality bombardment potentialities, carefully avoiding from becoming sorcerer's apprentices. Certainly good designers will be able to grasp the possibilities offered by today's most performing technologies, and are waiting so that these potentialities decant in order to configure the new changing life scenes.

(Measurements) We should improve these studies and make them more effective to define better our well-being, in relation to animal species, as well as with vegetation and even with the mineral world, taking advantage of the time lap manifestations of the space portions. Therefore, continuously through Space and Time measurements, in which we are immersed. (Relationships) The topic is clearly highlighted long ago. Respect to today the risk emergence is even more evident, recommending a very supervised use of artificial intelligence. The enormous mass information in which artificial intelligences are continuously self-instructed, reach incongruous actions, treating the data in statistical form that generate a secluded perception with the serious damage in dismantling human critical conscience.

\section{References}

Manganaro Mario (2000).Appunti sulla storia delle coniche. In Quaderno. Dipartimento di Architettura ed Urbanitica dell'Universitc̀ degli Studi di Catania, 19, pp. 21 -36.

Pizza Antonio (2004). Progetti e costruzioni. Alberto Campo Baeza. Milano: Mondadori Electa.

Sedlmayr Hans (2009). La luce nelle sue manifestazioni artistiche. Milano: Aesthetica

Siegfried Giedion ( 1984). Spazio, tempo ed architettura.Torino: Hoepli.

Sinisgalli Rocco, Vastola Salvatore (1994). La rappresentazione degli orologi solari di Federico Commandino. Firenze: Cadmo.

\section{Authors}

Claudio Marchese, Dept. of Engineering, University of Messina, claudio.marchese@unime.it

Antonino Nastasi, Dept. of Engineering, University of Messina, antonino.nastasi@unime.it 
